\title{
Endoanal ultrasonographic evaluation of an unhealed anal fissure after the lateral internal sphincterotomy
}

\author{
Yucel E, Akin ML, Sucullu I, Filiz AI, Ozdemir Y, Yildiz M \\ Gulhane Military Medical Academy, Haydarpasa Training Hospital, Department of General Surgery, \\ Uskudar, Istanbul, Turkey. erguntuna19@yahoo.com
}

\begin{abstract}
Objectives: The aim of this study was to evaluate the outcomes of the lateral internal sphincterotomy in patients who had unhealed anal fissures using the endoanal ultrasonography.

Background: Lateral internal sphincterotomy is an effective method in treatment of chronic anal fissures, but it is associated with 1 to $5 \%$ unhealing and recurrence rates. Endoanal ultrasonography can be used to evaluate the sphincterotomy and the efficiency of the treatment.

Methods: Totally, 40 patients with unhealed anal fissures after the lateral internal sphincterotomy were enrolled consecutively. The fissures were diagnosed by proctologic examination in every patient. The results of sphincterotomy were evaluated by the endoanal ultrasonography.

Results: There were 23 men and 17 women with the median age 29.7 years (range, 20-44 years). Using the endoanal ultrasonography, an incomplete internal sphincterotomy was detected in 26 of patients. In 12 patients, while the internal sphincter was completely intact, a superficial (subcutaneous) external anal sphincterotomy was found. In two patients, although the internal sphincterotomy was observed to be sufficient, a localized abscess formation of less than $1 \mathrm{~cm}$ was detected at the anal crypts level.

Conclusion: The use of endoanal ultrasonography in patients with unhealed or recurrent anal fissure is a beneficial diagnostic method in assessing the situations of sphincters after the lateral internal sphincterotomy. Although the lateral internal sphincterotomy is a successful surgical treatment and can be performed easily as an outpatient procedure, it should be performed with the correct and rigorously surgical technique (Tab. 2, Fig. 3, Ref. 31). Full Text in PDF www.elis.sk.

Key words: anal fissure, lateral internal sphincterotomy, unhealing, endoanal ultrasonography.
\end{abstract}

Chronic anal fissure (CAF), a linear ulcer situated in the distal anal canal, is a common anorectal condition, especially in young adults, with a roughly equal incidence in genders $(1,2)$. It is characterized by pain and bleeding at defecation and anal spasm $(3,4)$. Acute anal fissures heal spontaneously or by conservative treatment in 80 to $90 \%$ of the cases $(1,4,5)$. The cause is not known, but patients usually have a very high maximum resting anal pressure (MRAP) $(3,6,7)$. It is associated with hypertonia of the anal canal and a reduction in mucosal blood flow, with microcirculatory disturbances and a poor healing tendency $(3,8)$. When the MRAP lowers, this allows the fissure to heal $(1,6,9)$ and blood flow to the ulcer region improves $(1,8,10)$.

The gold standard treatment for CAF is a surgical reduction of MRAP $(1,6,9)$. Anal dilatation and lateral internal sphincterotomy (LIS) lower MRAP and the ulcer heals in most cases (1, $6,10)$. The results of prospective trials and meta analysis showed that LIS is superior to chemical treatment modalities like glyceril trinitrate, isosorbid di nitrate, topical diltiazem or nifedipine (11, 12). The standard sphincterotomy is a division of the internal anal

Gulhane Military Medical Academy, Haydarpasa Training Hospital, Department of General Surgery, Uskudar, Istanbul, Turkey

Address for correspondence: E. Yucel, MD, GATA Haydarpasa Egitim Hastanesi, Genel Cerrahi Servisi, Uskudar, 34668, Istanbul, Turkey. Phone: +90.216.5422020, Fax: +90.216.4494480 sphincter (IAS) from its lower edge to the level of dentate line, but it is not clear what amount of sphincter is cut $(13,14)$. On the other hand, limited sphincterotomy could be ineffective when the sphincter is long, as in young men, with the persistence or recurrent of fissure or symptoms $(5,12,15)$. The effectiveness of LIS and patients' subjective complaints can be objectively evaluated by anal manometer and endoanal ultrasonography (16-19).

In the study, the effectiveness of LIS in patients with persistent or recurrent fissure symptoms was assessed by anal manometer and endoanal ultrasonography (EAUS).

\section{Materials and methods}

Totally, 40 patients who had unhealed anal fissures after LIS were enrolled consecutively between 2006 and 2009. This number also included the patients who were operated on in other centers. The unhealed anal fissures were diagnosed by proctologic examination in each patient. All patients were evaluated by EAUS. EAUS was done in the left lateral position by one examiner using a B-K Medical ultrasound system with $10-13-16 \mathrm{MHz}, 360^{\circ}$ rotating endoprobe (Pro Focus 2050, Denmark) following a physical examination.

The anal canal was separated into the three levels during the endoanal ultrasonographic examination. Low anal canal was represented by subcutaneous external anal sphincter muscle and the most inferior fibers of internal anal sphincter muscle as a thin layer. 
Medium anal canal was represented by superficial and deep part of external anal sphincter muscle and the most marked thick fibers of internal anal sphincter muscle and high anal canal, as puborectalis muscle, and less marked internal anal sphincter muscle. The results of the operative interventions were classified as following:

- Adequate internal sphincterotomy

- Defect of internal anal sphincter muscle in low and medium anal canal with semicircular internal sphincter appearance.

- Subcutaneous external sphincterotomy

- Defect just in subcutaneous external sphincter muscle fibers, complete internal sphincter muscle.

- Incomplete internal sphincterotomy

1. Defect in subcutaneous external sphincter muscle fibers, short segment defect or thinning in the inferior part of internal sphincter muscle (subcutaneous external sphincterotomy with incomplete internal sphincterotomy).

2. Defect or thinning in the inferior part of internal sphincter muscle with intact medium anal canal (incomplete superficial internal sphincterotomy).

3. Partial internal sphincter muscle defect in low and medium anal canal with patent circular appearance (incomplete deep internal sphincterotomy).

Anal resting and squeeze pressures were measured by the eight-channel water perfusion catheter manometer (Mui Scientific, Mississaugo, Ontario, Canada) using Albyn Medical Phoenix V1.8.9 program.

\section{Results}

There were 23 men and 17 women with the median age 29.7 years (range, 20-44 years). The fissure was on the posterior midline in 24 patients, anterior in 6 , and on both sides in 6 of the 40 patients. However, in two patients, we didn't see any abnormal finding. Normal anal sphincters structures and the defect in internal anal sphincter after a successful internal sphincterotomy are shown in Figures 1a and 1b. The results of the endoanal ultrasonography are shown in Table 1. Using EAUS, an incomplete in-
Tab. 1. The results of endoanal ultrasound.

\begin{tabular}{lc}
\hline Findings & Number \\
\hline Incomplete internal sphincterotomy & 26 \\
$\begin{array}{l}\text { Superficial external sphincterotomy } \\
\text { (intact internal sphincter) }\end{array}$ & 12 \\
Small crypt abscess & 2 \\
\hline
\end{tabular}

ternal sphincterotomy was detected in 26 of patients (Fig. 2a). In 12 of patients, while the internal sphincter was completely intact, superficial (subcutaneous) external anal sphincterotomy was found (Fig. 2b). In two patients, although the internal sphincterotomy was observed to be sufficient, localized abscess formation of less than $1 \mathrm{~cm}$ was detected at the anal crypts level (Fig. 3). Manometric anal canal measurements are shown in Table 2.

\section{Discussion}

Anal fissure is a common and painful disorder. Lateral internal sphincterotomy is the choice of treatment of anal fissure. In the study, totally 40 patients with unhealed fissures were enrolled consecutively in a five years period. An incomplete internal sphincterotomy (65\%) and intact internal sphincter with superficial external sphincterotomy (30\%) was detected by endoanal ultrasonography in 38 (95\%) patients. Small crypt abscesses were found in the remaining two patients.

The standard sphincterotomy is a division of the internal anal sphincter (IAS) from its lower edge to the level of dentate line, but it is not clear what amount of sphincter is cut. It is generally accepted that this distance is about $1.5 \mathrm{~cm}$, but the amount of divided IAS is usually $50-60 \%(8-10)$, and can reach $7 \%(20,21)$. On the other hand, the limited sphincterotomy could be ineffective when the sphincter is long, as in young men, with the persistence or recurrent of fissure or symptoms. The frequency of this complication has been reported as 3.8 to $15.4 \%(12,15,22-24)$.

The aim of LIS is to decrease the pressure in the anal canal. It has been shown that anal pressure decreased up to $50 \%$ in patients with high anal pressure and healed fissures (16). On the other hand,
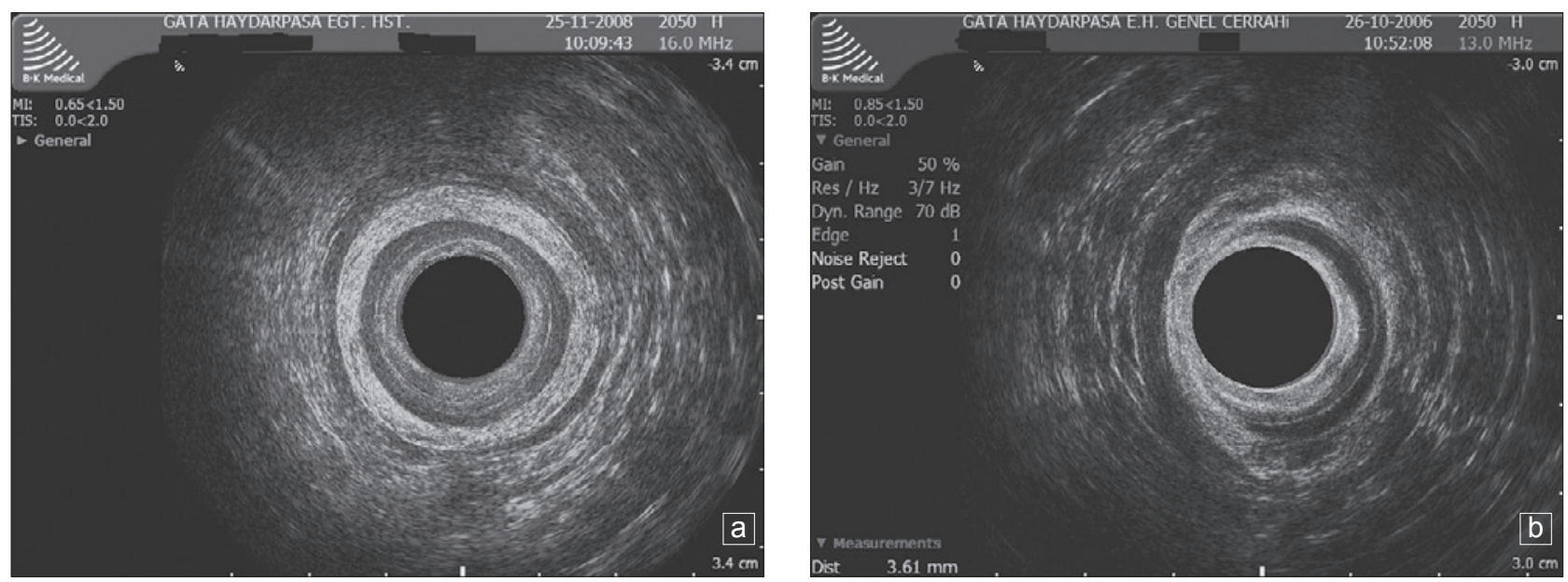

Fig. 1. (a) Normal anal findings and (b) a defect in internal anal sphincter after a successful sphincterotomy. 

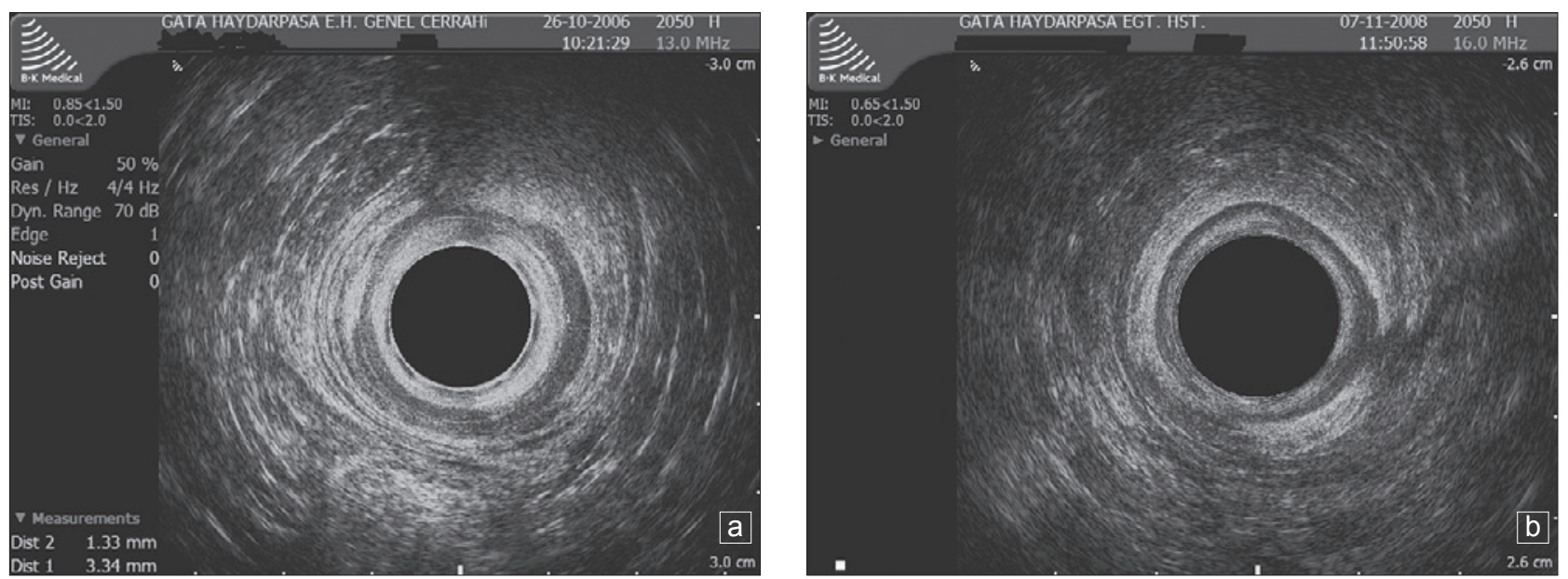

Fig. 2. (a) Incomplete internal sphincterotomy and (b) an intact internal sphincter with superficial (subcutaneous) external anal sphincterotomy.

the decreased pressure after LIS has elevated above that of control patients 12 months later (17). Even though patients with CAFs have a higher than normal resting anal pressure $(6,7)$, in the study of Parellada (3), only $24 \%$ of the patients had pressure above 100 $\mathrm{cmH}_{2} \mathrm{O}$, and the rest $(76 \%)$ had normal or decreased IAS pressure (normal range, 55-120 $\mathrm{cmH}_{2} \mathrm{O}$ for both sexes). The patients may have had lower anal pressure preceding the development of their fissure after sphincterotomy. Therefore 'normal' values after operation may be considered abnormal compared to the pre-existing values. Nevertheless, a reduction in the internal sphincter tone reflected by a decrease in the anal resting pressure may allow a sufficient resumption of anodermal blood supply for fissure healing in most patients.

The mean resting anal sphincter pressures were found to be higher than normal values, which may reflect the persistence and recurrence of fissures. We did not know the previous anal sphincter pressures of all the patients since some of them came from other centers. On the other hand, the sphincter pressures alone seem not to be a reliable indicator of persistence or recurrence of fissures according to the previous studies $(3,6,7,16,17)$.

The use of EAUS in anorectal surgery has improved our understanding of postoperative changes and preoperative evaluation of the patients. An inadequate sphincterotomy is the most common reason of the unhealed anal fissures. In the study by Farouk et al (25), including 13 adult patients with a persistent CAF, EAUS showed that 2 of them had a limited division of the internal anal sphincter with the intact external sphincter. The remaining 11 patients had defects of the external sphincter along the previous site of surgery. The authors have found that the failure of a fissure to heal after sphincterotomy relates to an inadvertent division of the external sphincter and the failure to divide the internal anal sphincter, or to a limited internal sphincterotomy. In another study

Tab. 2. The manometric results in females and males (mean $\pm \mathrm{SD}$ ).

\begin{tabular}{lccc}
\hline Gender & $\mathrm{n}$ & Resting pressure & Squeeze pressure $^{* *}$ \\
\hline Females & 17 & $94 \pm 17 \mathrm{mmHg}$ & $132 \pm 21 \mathrm{mmHg}$ \\
Males & 23 & $104 \pm 19 \mathrm{mmHg}$ & $140 \pm 24 \mathrm{mmHg}$ \\
\hline
\end{tabular}

"Estimated normal range of anal canal resting pressure $=40-70 \mathrm{mmHg},{ }^{* *}$ Estimated normal range of anal canal squeeze pressure $=70-110 \mathrm{mmHg}, \mathrm{SD}=$ standard deviation

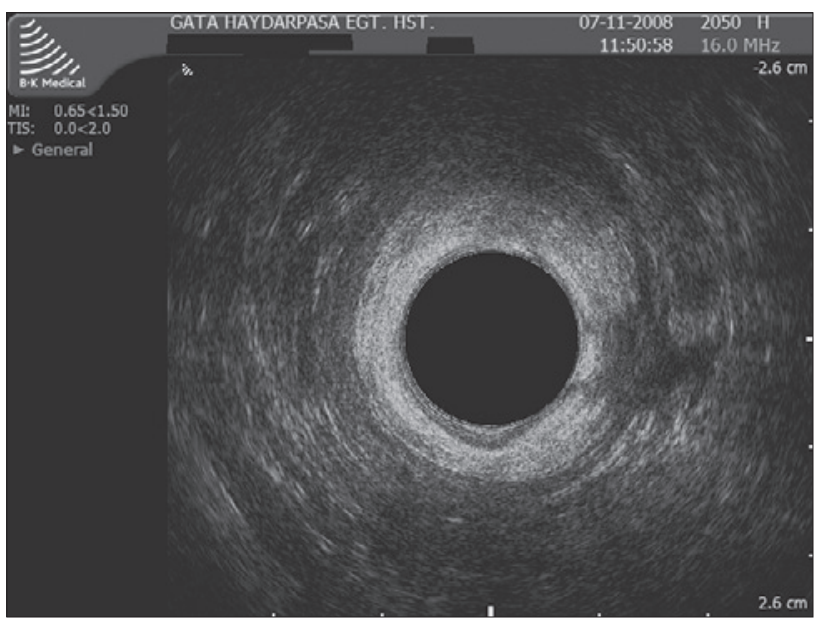

Fig. 3. Localized abscess formation after an external anal sphincterotomy.

by Garcia-Granero et al (18), including 10 patients with symptomatic recurrent anal fissure after closed LIS, EAUS showed that a complete internal sphincter defect was identified in only $10 \%$ (1 patient) and an incomplete internal sphincter defect in $90 \%$ of the patients in the recurrence group. An incomplete sphincterotomy was associated with a significant symptomatic anal fissure recurrence. In our study, an incomplete internal sphincterotomy and intact internal sphincter with a superficial external sphincterotomy were detected by EAUS in $95 \%$ of patients.

The clinical evidence suggests that an incomplete division of the internal anal sphincter results in a recurrent fissure (26). Technical failure of LIS has been demonstrated by EAUS (25). This method has been used to assess the morphology of the internal anal sphincter $(27,28)$ and its thickness $(27-29)$ and to detect unsuspected damage after an anorectal surgery (30). Previously published data have demonstrated that EAUS could evaluate the extent of internal anal division caused by LIS (31).

The anal sphincter pressures may not be a reliable diagnostic parameter for persistent and recurrent anal fissures, since patients may have higher than normal resting anal pressures $(6,7)$ 
or normal or decreased resting anal pressures (3), or preoperative pressure values may not be known. On the other hand, EAUS is a useful method for the evaluation of the anatomic effectiveness of lateral internal sphincterotomy and diagnosis of persistent CAFs more than any other method. The morphology and thickness of both internal and external sphincters can be evaluated by EAUS.

We believe that LIS should be performed with the correct technique and also should be controlled carefully in surgery education.

\section{Conclusion}

EAUS is a beneficial diagnostic method in assessing the efficiency of the surgical procedure after LIS and in determining different pathologies. In case of an unhealed fissure after LIS, if the medical treatment modalities are not successful, the future surgical treatment strategies such as ipsilateral internal sphincerotomy, contralateral internal sphincerotomy, and advancement flaps, can be planned according to the EAUS findings. LIS should be performed with the correct and rigorous surgical technique.

\section{References}

1. Katsinelos P, Papaziogas B, Koutelidakis I et al. Topical $0.5 \%$ nifedipine vs. lateral internal sphincterotomy for the treatment of chronic anal fissure: long-term follow-up. Int J Colorectal Dis 2006; 21: 179-183.

2. Jonas M, Scholefield JH. Anal fissure. Gastroenterol Clin North Am 2001; 30: 167-174.

3. Parellada C. Randomized, prospective trial comparing $0.2 \%$ isosorbide dinitrate ointment with sphincterotomy in treatment of chronic anal fissure: A two-year follow-up. Dis Colon Rectum 2004; 47: 437-443.

4. Lund JN, Armitage NC, Scholefield JH. Use of glyceryl trinitrate ointment in the treatment of anal fissure. Br J Surg 1996; 83: 776-777.

5. Rosa G, Lolli P, Piccinelli D et al. Calibrated lateral internal sphincterotomy for chronic anal fissure. Tech Coloproctol 2005; 9: 127-132.

6. McNamara MJ, Percy JP, Fielding IR. A manometric study of anal fissure treated by subcutaneous lateral internal sphincterotomy. Ann Surg 1990; 211: 235-238.

7. Farouk R, Duthie GS, MacGregor AB, Bartolo DC. Sustained internal sphincter hypertonia in patients with chronic anal fissure. Dis Colon Rectum 1994; 37: 424-429.

8. Schouten WR, Briel JW, Auwerda JJ. Relationship between anal pressure and anodermal blood flow: the vascular pathogenesis of anal fissures. Dis Colon Rectum 1994; 37: 664-669.

9. Rosen L, Abel ME, Gordon PH et al. Practice parameters for the management of anal fissure. The Standards Task Force. American Society of Colon and Rectal Surgeons. Dis Colon Rectum 1992; 35: 206-208.

10. Schouten WR, Briel JW, Auwerda JJ, De Graaf EJ. Ischaemic nature of anal fissure. Br J Surg 1996; 83: 63-65.

11. Nelson RL. Meta - analysis of operative techniques for fissure in ano. Dis Colon Rectum 1999; 42: 1424-1431.

12. Evans J, Luck A, Hewett P. Glycryl trinitrate vs lateral sphincterotomy for chronic anal fissure: prospective, randomized trial. Dis Colon Rectum 2001; 44: 93-97.

13. Eisenhammer $\mathbf{S}$. The evaluation of the internal anal sphincterotomy operation with special reference to an anal fissure. Surgery Gynec Obstet 1959; 109: 583-590.
14. Coller JA, Karulf RE. Anal fissure. 15-19. In: Fazio VW (ed). Current therapy in colon and rectal surgery. Philadelphia; B. C. Decker, 1990.

15. Nyam DC, Pemberton JH. Long-term results of lateral internal sphincterotomy for chronic anal fissure with particular reference to incidence of fecal incontinence. Dis Colon Rectum 1999; 42: 1306-1310.

16. Ezri T, Susmallian S. Topical nifedipine vs. topical glyceryl trinitrate for treatment of chronic anal fissure. Dis Colon Rectum 2003; 46: 805-808.

17. Ram E, Alper D, Stein GY, Bramnik Z, Dreznik Z. Internal anal sphincter function following lateral internal sphincterotomy for anal fissure: a long-term manometric study. Ann Surg 2005; 242: 208-211.

18. Garcia-Granero E, Sanahuja A, Garcia-Armengol J, et al. Anal endosonographic evaluation after closed lateral subcutaneous sphincterotomy. Dis Colon Rectum 1998; 41: 598-601.

19. Shelygin IA, Zharkov EE, Orlova LP, Podmarenkova LF, Poletov NN. Long term results of excision of anal fissure in combination with lateral subcutaneous sphincterotomy. Khirurgiia (Mosk) 2005; 7: 33-39.

20. Nielsen MB, Rasmussen OO, Pedersen JF, Christiansen J. Risk of sphincter damage and anal incontinence after anal dilatation for fissurein-ano. An endosonographic study. Dis Colon Rectum 1993; 36: 677-680.

21. Abcarian H. Surgical correction of chronic anal fissure: results of lateral internal sphincterotomy vs. fissurectomy-midline sphincterotomy. Dis Colon Rectum 1980; 23: 31-36.

22. Lewis T, Corman M, Prager E, Robertson W. Longterm result of open and close sphincterotomy for anal fissure. Dis Colon Rectum 1988; 31: 368-371.

23. Weaver RM, Ambrose NS, Alexander-Williams J, Keighley MR. Manual dilatation of the anus vs. lateral subcutaneous sphincterotomy in the treatment of chronic fissure-in-ano. Results of a prospective, randomized, clinical trial. Dis Colon Rectum 1987; 30: 420-423.

24. Oh C, Divino CM, Steinhagen RM. Anal fissure. 20-year experience. Dis Colon Rectum 1995; 38: 378-382.

25. Farouk R, Monson JR, Duthie GS. Technical failure of lateral sphincterotomy for the treatment of chronic anal fissure: a study using endoanal ultrasonography. Br J Surg 1997; 84: 84-85.

26. Keighley MR, Greca F, Nevah E, Hares M, Alexander-Williams J. Treatment of anal fissure by lateral subcutaneous sphincterotomy should be under general anaesthesia. Br J Surg 1981; 68: 400-401.

27. Law PJ, Kamm MA, Bartram CI. Anal endosonography in the investigation of faecal incontinence. Br J Surg 1991; 78: 312-314.

28. Nielsen MB, Pedersen JF, Rasmussen O, Christiansen J. Endosonography of the anal sphincter: findings in healthy volunteers. AJR Am J Roentgenol 1991; 157: 1199-1202.

29. Gantke B, Schafer A, Enck P, Ltibke HJ. Sonographic, manometric, and myographic evaluation of the anal sphincters morphology and function. Dis Colon Rectum 1993; 36: 1037-1041.

30. Felt-Bersma RJ, van Baren R, Koorevaar M, Strijers RL, Cuesta MA. Unsuspected sphincter defects shown by anal endosonography after anorectal surgery. A prospective study. Dis Colon Rectum 1995; 38 : 249-253.

31. Sultan AH, Kamm MA, Nicholls RJ, Bartram CI. Prospective study of the extent of internal anal sphincter division during lateral sphincterotomy. Dis Colon Rectum. 1994; 37: 1031-1033.

Received January 25, 2010. Accepted September 20, 2012. 